\title{
AS IMPLICAÇÕES DO PROGRAMA DE TRANSFERÊNCIA DE RENDA BOLSA FAMÍLIA NA ALFABETIZAÇÃO DOS BENEFICIADOS NO MUNICÍPIO DE SANTA MARIA - RS
}

\section{AS INCOME TRANSFER PROGRAM IMPLICATIONS OF LITERACY IN BAG FAMILY BENEFIT IN SANTA MARIA$$
C I T Y-R S
$$

\author{
Rita Inês Paetzhold Pauli \\ Universidade Federal de Santa Maria - Santa Maria - RS - Brasil \\ Laura Corino Haesbaert \\ Universidade Federal de Santa Maria - Santa Maria - RS - Brasil
}

\begin{abstract}
Resumo: $O$ artigo apresenta o desenvolvimento do Programa Bolsa Família-PBF no Município de Santa Maria - RS. Tem como objetivo central mostrar os impactos na alfabetização a partir da sua implementação e caracterizar de forma mais abrangente as variáveis: a) renda per capita das famílias; b) condições infraestruturais dos domicílios e c) frequência escolar dos estudantes vinculados ao Programa. A metodologia compreende uma análise econométrica e pesquisa de campo. Os dados utilizados são provenientes dos Censos Demográficos do Instituto Brasileiro de Geografia e Estatístico-IBGE de 2000 e 2010, de informações da Secretaria de Municipal de Assistência Social, Cidadania e Direitos Humanos-SMAC e de informações obtidas pela pesquisa de campo realizada nos meses de maio e junho de 2012 . Os resultados mostram que quanto maior a proporção de pessoas receptoras dos benefícios do PBF no município, maior o acréscimo na proporção de alfabetizados. Salienta-se o elevado grau de repetência escolar (44\% das famílias tiveram reprovação de pelo menos um dos filhos). O Programa per si não é capaz de diminuir todas as adversidades que se impõem sendo, de fato, necessárias políticas macroeconômicas mais amplas de crescimento econômico que, por sua vez, devem repercutir no aumento da renda per capita combinada com distribuição de renda.
\end{abstract}

Palavras-chave: Programa Bolsa Família. Alfabetização. Política Pública.

Abstract: This paper presents the development of the Low Income Family Benefic (Bolsa Família) program in the municipality of Santa Maria-RS and has as main its main objective to show impacts on literacy from the implementation of the family allowance in the municipality and characterise more comprehensively the situation of variables 
such as per capita family income, the infrastructural conditions of households and school attendance of students linked to the Program. The methodology used was, in addition to a literature review, an econometric analysis and a field research. The data used were from the IBGE's demographic census of 2000 and 2010, information from the Municipal Secretariat of Social Assistance, Citizenship and Human Rights (SMAC) and from field research carried out in the months of May and June 2012. The results show that the higher the proportion of people who receive low income family benefit (Bolsa Família) in the municipality, the greater the increase in the proportion of literacy. It emphasizes the hight degree of school repetition was noted $44 \%$ of households had children reproved in the school year. The program itself is not able to lower all the adversities. It is, indeed, necessary to broader macroeconomic policies of economic growth that, in turn, must result in increased per capita income combined with income distribution.

Keywords: Low income family benefit Bolsa program. Literacy. Public policy. 


\section{INTRODUÇÃO}

O Programa Bolsa Família, implementado pelo governo federal brasileiro em outubro de 2003, tem como objetivo combater a pobreza, a fome e garantir a inclusão escolar no país. Nessa perspectiva, não se pode deixar de reiterar que tal iniciativa representa inovações no padrão histórico de intervenção pública na área social. Em Santa Maria- RS, o PBF foi implantado em 2004.

Trata-se de mais uma política social que vem ao encontro da necessidade de atender direitos universais estabelecidos constitucionalmente. Na verdade, esse processo permitiu a inclusão, no Sistema de Proteção Social, da prática de Programas de Renda Mínima, ou também chamados Programas de Transferência de Renda, como possibilidade para o enfrentamento da pobreza.

Considerando-se a construção histórica dos Programas de Transferência de Renda no Brasil, no âmbito do Sistema Brasileiro de Proteção Social, especialmente a partir dos anos 1990, este artigo tem como objetivo central mostrar os impactos na alfabetização a partir da implementação do PBF no Município de Santa Maria, e caracterizar de forma mais abrangente a situação de variáveis como renda per capita das famílias e na frequência escolar dos estudantes vinculados ao PBF do município.

Quanto à questão do lócus escolhido - Santa Maria - RS -, decorreu não apenas devido à falta de análises acerca da temática abordada, mas, também por se tratar de um município que assume um papel de referência para região central do Estado. Certamente, o aprofundamento desse debate de forma geral e, a perquirição das diferentes facetas que compõem a relação educação e Bolsa Família torna-se relevante na medida em que propõe a verificação de benefícios, falhas e eficácia do PBF no município desde sua implementação.

Para isso, este artigo está organizado em seis seções, incluindo esta. Na segunda seção apresenta as relações entre o Estado e o Sistema de Proteção Social no Brasil; a terceira, recompõe o processo histórico de desenvolvimento dos Programas de Transferência de renda no Brasil. A quarta seção remete à abordagem acerca da abrangência e gestão do PBF. A quinta seção mostra os impactos do Programa Bolsa Família na Alfabetização dos Beneficiários do Programa no Município de Santa Maria - RS. 
O quinto capítulo expõe os resultados obtidos na pesquisa de campo dos beneficiários do Programa, com incursões específicas nas seguintes variáveis: Grau de Escolaridade das Beneficiárias do PBF; Relação de Trabalho; Tipos de Desempregos; Renda Familiar; Estado Civil; Número de Filhos por Famílias; Acesso à Saúde; Acesso à Educação e Conhecimento das Condicionalidades do PBF e, finalmente, as considerações finais.

\section{AS RELAÇÕES ENTRE O ESTADO VIS $A$ VIS O SISTEMA DE PROTEÇÃO SOCIAL NO BRASIL}

Com relação ao Estado e o Sistema de Proteção Social, deve-se destacar que o governo é responsável pela execução das Políticas Sociais, cujos Programas de Transferência de Renda são, hoje, uma das ações mais atuantes em nível de Política Pública de Assistência Social que interage com as políticas de educação e saúde.

O Sistema de Proteção Social no Brasil, ao qual estão vinculados os Programas de Transferência de Renda, conceituam-se, segundo Silva e Giovanini (2004), como segue: sistemas de Proteção são as formas, às vezes mais, às vezes
menos institucionalizadas que todas as sociedades humanas
desenvolvem para enfrentar vicissitudes de ordem biológica ou
social que coloquem em risco parte ou totalidade de seus
membros (SILVA; GIOVANI, 2004, p. 15).

Uma das características mais marcantes das formas e Sistemas de Proteção Social, dos mais simples aos mais complexos, é o de implicar sempre uma transferência de recursos sociais, sob a forma de bens e serviços, por meio de Políticas Sociais. No caso brasileiro, vinculadas, na sua grande maioria, ao Poder Público.

A Política Social é um canal utilizado para a execução de programas para o atendimento da população. É no espaço das instituições, principalmente públicas, que as Políticas Sociais são desenvolvidas, sendo que a cada instituição social determinada cabe a atuação em uma também determinada área de carência da população (BALDISSERA, 1997, p. 39).

A partir de um conjunto de objetivos, estrutura-se um amplo debate sobre as políticas sociais que se incorporarão à agenda 
constituinte ${ }^{1}$. A Constituição de 1988 espelhará os ideais universalistas acoplados a uma ideia ampliada de cidadania, em busca da expansão da cobertura de políticas sociais no que diz respeito a bens, serviços, garantias de renda e equalização de oportunidades. Ela tentará superar um sistema marcado pelo autofinanciamento, excludente e não distributivo, procurando instituir as bases para a organização de um sistema universal e garantidor de direitos².

O Estado elabora políticas sociais pontuais para atender necessidades e encontra legitimação precisamente em sua vertente social, concretizada no reconhecimento dos direitos sociais e na obrigação de materializar um bem- estar generalizado a todos os cidadãos. Esses objetivos estão diretamente ligados ao sistema de prestações e às políticas sociais. O êxito ou o fracasso na realização das políticas sociais condiciona a legitimação do Estado Social (PISÓN, 1998). É preciso, porém, deixar claro que esse Estado Social assume feições muito diferenciadas nos diversos países onde o capitalismo se instala como modelo hegemônico (COUTO, 2004).

Fica claro que as definições das políticas sociais, em grande parte, estão sujeitas à dinâmica das relações estabelecidas entre os diversos atores da sociedade local, a partir das particularidades e necessidades específicas. Os atores organizados possibilitam tornar público, efetivo e democrático o debate dos interesses individuais, dos interesses dos

\footnotetext{
1 Segundo Vianna e Silva (1989), os eixos da agenda reformadora das políticas sociais eram: descentralização na execução, controle social das políticas e programas, integração das políticas, democratização do acesso aos bens públicos e universalização da Seguridade Social, tecnologias adequadas e maior comprometimento das fontes fiscais no financiamento.

2 De fato, no campo da proteção a riscos sociais, a Constituição procurou dar garantias de financiamento que pudessem sustentar a incorporação dos grupos sociais ainda excluídos daquela forma de cobertura. Este esforço foi consolidado em um sistema misto, cujo acesso se dá, no âmbito da Previdência Social, pela via da contribuição. Contudo, para ampliar a cobertura, a Constituinte flexibiliza as fontes de financiamento e formas de contribuição da Previdência Social, dando margem à inclusão dos trabalhadores rurais em regime de economia familiar. Paralelamente, a nova Carta Magna determinou a constituição de políticas de proteção de caráter não contributivo, a Assistência Social. Não houve, porém, a explicitação da cobertura obrigatória a todos os cidadãos, e a regulamentação de ambas as políticas afastou-as de um padrão mais integrado de proteção social que pudesse ser identificado em uma cobertura universal. Sobre a reestruturação do SBPS a partir da Constituição de 1988 (Ver Draibe, 1989).
} 
agentes econômicos e dos interesses da coletividade, avançando para a constituição de espaços de consenso político para além das contradições existentes na relação capital-trabalho (POCHMANN, 2004).

Essa incorporação de privilégios impede a formação de uma classe trabalhadora autônoma e possuidora de uma identidade coletiva, na medida em que reforça a sua fragmentação por meio da distribuição diferencial de benefícios.

A opção é centrar todas as forças na reversão desse processo, buscando construir uma reforma do Estado verdadeiramente pública, "intelectual e moral", com intensa participação da sociedade civil, ampliando a sua unidade para além do terreno $\mathrm{da}$ institucionalidade e adentrando nas questões da racionalidade econômica e da distribuição da riqueza (SIMIONATO, 2007, p. 11)

O desafio é garantir às Políticas Sociais inscritas no Sistema de Proteção Social um conjunto de medidas para a produção e a reprodução da vida com mediações necessárias para a construção das condições de protagonismo e de autonomia das classes subalternas (BOSCHETTI, 2005). Nessa perspectiva, as políticas sociais, como um dos legítimos espaços públicos de resistência, podem adensar relações favoráveis à hegemonia do trabalho e, para além dessa hegemonia, avançar nas conquistas democráticas pela defesa e universalização dos direitos sociais.

\section{BREVE HISTÓRICO DOS PROGRAMAS DE TRANSFERÊNCIA DE RENDA NO BRASIL}

Os Programas de Transferência de Renda constituem importante política pública no Sistema de Proteção Social do Brasil na atualidade à medida que são executados conjuntamente com outras Políticas Sociais, e não somente com repasse de recursos financeiros à população que se encontra excluída socialmente.

Os Programas de Transferência de Renda são entendidos como aqueles que atribuem uma transferência monetária aos indivíduos ou às famílias, mas que também possuem outras medidas situadas principalmente no campo das políticas de 
educação, saúde, assistência social e trabalho, representando, portanto, elementos estruturantes, fundamentais, para permitir o rompimento do ciclo vicioso que aprisiona grande parte da população brasileira nas amarras da reprodução da pobreza (SILVA; GIOVANNI, 2004, p. 19). 
A análise de Silva et al., (2004) mostra que o debate em torno dos Programas de Transferência de Renda os situa como "possibilidade de solução para a crise do desemprego, e o enfrentamento da pobreza, sendo defendidos por políticos, organizações sociais e estudiosos das questões sociais de diferentes matizes teóricas".

A primeira iniciativa dessa natureza ocorreu em 1991, com o Projeto de Lei $n^{\circ} 80$, que instituía o Programa de Garantia de Renda Mínima, apresentado pelo Senador, por São Paulo, Eduardo Suplicy (PT), que visava a esse tipo, também, de orientação transformadora e redistributiva. O projeto de Lei do Senador foi fundamentado e justificado com base no art. $3^{\circ}$, inciso III, da Constituição Brasileira de 1988, que determina erradicar a pobreza e a marginalização e reduzir as desigualdades sociais e regionais. Indicava a transferência da renda monetária, em forma de renda mínima, como mecanismo a ser atribuído para aqueles incapacitados de satisfazer suas necessidades básicas (MOURA, 2009).

Segundo Suplicy (2002), tratava-se de um imposto de renda negativo para beneficiar todos os residentes do país, maiores de 25 anos, que auferissem menos de 45 mil cruzeiros, moeda da época, correspondendo a cerca de 2,25 salários mínimos. Era corrigido, nos meses de maio e novembro, sempre que a inflação atingisse $30 \%$, com um acréscimo real no mês de maio de cada ano, igual ao crescimento real, por habitante, do Produto Interno Bruto-PIB do ano anterior.

O marco inicial, conforme indicado, foi a apresentação e a aprovação da proposta do Programa de Garantia de Renda Mínima do Senador Eduardo Suplicy, em 16 de dezembro de 1991, permanecendo, desde 1993, na Câmara dos Deputados, na comissão de Finanças e Tributação, com parecer favorável. Todavia, o projeto foi obstruído no Congresso Nacional e pressionado pela tramitação de vários outros projetos propondo programas similares.

Conforme estudo realizado por Silva e Silva (2006) em 1995, pode-se vislumbrar as primeiras experiências do Programa de Renda Mínima/Bolsa Família. Inicialmente em Campinas, Brasília e Ribeirão Preto, e estendendo-se para vários municípios e estados brasileiros. Em 1996, foram iniciadas as primeiras experiências de iniciativa do governo federal, com o Programa de Erradicação do Trabalho Infantil-PETI e o 
Benéfico de Prestação Continuada-BPC. Em 1999, foram iniciadas as experiências Estaduais 3 .

Ainda, no governo de Fernando Henrique Cardoso, em 2001, foram ampliados os programas federais com a criação do Programa Bolsa Escola e Bolsa Alimentação. Essa ação do governo intensificou os debates em defesa de uma Renda de Cidadania para todos os brasileiros. Em 2003, o Presidente Luiz Inácio, ao assumir o governo, adotou como meta principal o enfrentamento da fome e da pobreza no país, colocando as Políticas Sociais como mecanismos de ação aos seus objetivos políticos e sociais, articulando-as a uma Política Econômica. Assim, lançou a proposta de unificação dos Programas de Transferência de Renda (SILVA; SILVA, 2006).

Dessa forma, inicia-se um processo de unificação dos programas federais de transferência de renda, sendo, inicialmente, unificados quatro programas, como: Bolsa-Escola, Bolsa-Alimentação, Vale-Gás e Cartão-Alimentação, envolvendo recursos financeiros de $R \$ 4,3$ bilhões para o ano de 2003 e de 5,3 bilhões em 2004. O novo programa, denominado de Bolsa-Família, prevê o atendimento de 3,6 milhões de famílias em 2003, apresentando uma meta para atendimento de 7,6 milhões de famílias em 2004, alcançando em média 11,0 milhões de famílias em março de 2010 (COLARES, 2012)

Em janeiro de 2004, foi criado o Ministério do Desenvolvimento Social e Combate à Fome-MDS, em substituição ao Ministério da Assistência Social e o Ministério Extraordinário de Segurança Alimentar e Combate à Fome, passando os Programas de Transferência de Renda a serem coordenados por este ministério por intermédio da Secretaria Nacional de Renda e Cidadania- SENARC 4.

3 O Estado do Amapá faz parte deste cenário com a implantação do Programa BolsaEscola Família, implantado no Governo de João Capiberibe em 1996, como uma medida emergencial destinada a reduzir o trabalho infantil, a violência, o abandono escolar e exclusão social de milhares de famílias. Fazendo parte de duas gestões governamentais, hoje na gestão do Governador Waldez Góes o programa é denominado Renda para Viver Melhor atendendo em média 19 mil famílias em todo o Estado do Amapá.

${ }^{4}$ Criada em janeiro de 2004, juntamente com o Ministério do Desenvolvimento Social e Combate à Fome, a Secretaria Nacional de Renda de Cidadania (SENARC) tem por objetivo a implementação da Política Nacional de Renda de Cidadania no país, teve sua estrutura e competências estabelecidas no artigo $7^{\circ}$ do Anexo I do Decreto $n^{\circ} 5.074$, de 11 de maio de 2004, maiores informações disponível em: www.mds.gov.br. 
A justificativa utilizada pelo Governo Federal para a unificação dos Programas de Transferência de Renda, conforme destaca a autora Silva e Giovani (2004) foi:

ampliação de recursos, elevação do valor monetário do benefício e melhor atendimento, a proposta de unificação tem como propósito mais amplo manter um único Programa de Transferência de Renda, articulando Programas Nacionais, estaduais e municipais em implementação, na perspectiva de instituição de uma Política Nacional de Transferência de Renda (SILVA; GIOVANI, 2004, p.136).

\subsection{A dimensão educação e a multidimensionalidade de ações integradas ao Programa de Transferência de Renda}

Além da existência de múltiplos fatores que integram os objetivos e ações dos Programas de transferência de renda, a literatura especializada mostra que a redução da pobreza presente nestes acaba por melhorar os níveis de educação nas famílias receptoras desses recursos. Conforme afirma Rocha (2003), embora a pobreza seja um fenômeno complexo, os estudos mostravam que havia correlação entre pobreza e baixo nível de escolaridade. A autora mostra que baixo nível de escolaridade não significa necessariamente condenação à pobreza, no entanto, entre os pobres, predominam indivíduos com baixo nível de escolaridade, "verificou-se que o baixo nível educacional - definido como menos de quatro anos de escolaridade- era a variável a qual estava associado a maior probabilidade de o indivíduo e de sua família serem pobres". Esse indicador vai orientar a ligação do programa de transferência de renda no Brasil à educação.

A pobreza apresenta dimensões histórica, econômica, social, cultural e política; é complexa e multidimensional. É produto da exploração do trabalho; é desigualdade na distribuição da riqueza socialmente produzida; é não acesso a serviços sociais básicos, ao trabalho e à renda digna; é não participação social e política (ROCHA, 2003).

Ao propor a integração dos programas de transferência de renda, o objetivo era integrar e direcionar as políticas para adquirir avanços 
sem paralisar o pagamento dos benefícios para as famílias que realmente precisassem. Buscava-se, também, aperfeiçoar os mecanismos de gestão para que o uso dos recursos fosse mais racional e houvesse uma articulação de iniciativas de diferentes pastas, bem como um estímulo para que a comunidade participasse da gestão (COLARES, 2012). Para Silva e Silva (2006), os Programas de Transferência de Renda no Brasil:

São marcados, por grandes inovações: a implementação descentralizada desses Programas; a transferência monetária direta para os beneficiários; a admissão da Família enquanto unidade de atenção social; a unificação dos programas; a proposta de articulação de políticas compensatórias co políticas estruturantes e a obrigatoriedade do cumprimento condicionalidades pó parte dos beneficiários, o que imprimiu ao Sistema Brasileiro de Proteção Social novo padrão, novo conteúdo, nova dinâmica, mas também novos desafios (SILVA; SILVA, 2006, p. 28)

Os desafios apontados pela autora são de natureza estrutural e relacionado às dificuldades para implementação na proposta de unificação ao serem considerados pelos formuladores e gestores desses programas.

\section{ABRANGÊNCIA E GESTÃO DO PROGRAMA BOLSA FAMÍLIA}

A criação do PBF, em outubro de 2003 , foi um passo decisivo para a ampliação e articulação da rede de proteção social brasileira. O PBF promoveu a unificação de quatro programas federais (Bolsa Escola, Bolsa Alimentação, Vale Gás e Cartão Alimentação).

Em 2002, a soma dos recursos empregados nos programas Bolsa Escola, Bolsa Alimentação e Auxílio Gás foram de $\mathrm{R} \$ 2,27$ bilhões. Nos anos seguintes, houve uma consistente evolução no volume de recursos transferidos às famílias. Outro ponto que merece destaque é a ampliação da participação do PBF na execução dos recursos financeiros ao longo do processo de expansão e "migração" de beneficiários dos programas remanescentes, virtualmente concluído em 2006, quando o PBF respondeu por $97 \%$ das transferências às famílias 5 .

\footnotetext{
${ }^{5}$ Algumas famílias beneficiárias remanescentes do Auxílio Gás não puderam migrar para o Bolsa Família até o final de 2006, por diferença no critério de elegibilidade
} 
Além da ampliação dos recursos federais, o PBF fomentou a integração da atuação federal com programas estaduais e municipais de transferência de renda, mediante termos de cooperação pactuados entre as partes ${ }^{6}$.

A unificação permitiu o aprimoramento dos mecanismos de gestão, a ampliação da cobertura e a elevação do valor médio dos benefícios, além de propiciar condições para o estabelecimento de relações intergovernamentais mais articuladas na implementação de ações de redução da pobreza. Conforme registram Fonseca e Vianna (2006):

\begin{abstract}
A unificação dos programas de transferência de renda deve-se à compreensão, por parte do governo, da necessidade de melhorar a gestão e aumentar a efetividade do gasto social, por meio da otimização, da racionalização e de ganhos de escala, e apóia-se na maior facilidade de interlocução do governo federal com Estados e municípios, tendo em vista que é vital definir funções para cada ente governamental e estabelecer termos de cooperação entre os três níveis de governo na operacionalização dos programas sociais (FONSECA; VIANNA, 2006, p.453).
\end{abstract}

Outra inovação do PBF, quando comparado aos programas federais de transferência de renda anteriores, foi a definição da família, em sua integralidade, como foco das ações de desenvolvimento social, e não de seus integrantes ou dimensões de sua vida (saúde, educação, alimentação, entre outros) tomada isoladamente.

Os objetivos básicos do PBF em relação a seus beneficiários são:

I. Promover o acesso à rede de serviços públicos, especialmente da Saúde, Educação e Assistência Social;

II. Combater a fome e promover a segurança alimentar e nutricional;

III. Estimular a emancipação sustentada das famílias que vivem em situação de pobreza e extrema pobreza;

(renda per capita inferior a $1 / 2$ salário mínimo, para o Auxílio Gás) (CAMPOS FILHO, 2007).

${ }^{6}$ No final de 2006, estavam em vigência acordos de integração que abrangiam copagamento com quatro Estados, dez municípios e o Distrito Federal, representando um aporte adicional de recursos às famílias. 
IV. Combater a pobreza;

V. Promover a intersetorialidade, a complementaridade e a sinergia das ações sociais do poder público? .

Percebe-se, portanto, a amplitude dos objetivos desse Programa e das demandas intrínsecas de articulação das diversas áreas de governo implicadas em sua gestão - Assistência Social, Educação, Saúde, Segurança Alimentar, Trabalho e outras - o que torna necessária a colaboração entre as distintas esferas do Poder Executivo, particularmente os municípios, tema a ser desenvolvido mais adiante.

A responsabilidade pela gestão do PBF cabe à Secretaria Nacional de Renda de Cidadania. Este órgão do MDS estabelece o relacionamento com os entes federados para a implementação do programa, negocia termos de cooperação para integração de programas próprios de estados e municípios ao PBF (as chamadas "pactuações"), negocia e acompanha a execução do contrato de prestação de serviços com o agente operador - a Caixa Econômica Federal (CEF), gerencia o Cadastro Único de Programas Sociais-CadÚnico em âmbito nacional, define as regras, fluxos e procedimentos da gestão de benefícios (inclusões, bloqueios, suspensões, cancelamentos), coordena a atuação dos ministérios setoriais no acompanhamento das condicionalidades e executa as repercussões pertinentes sobre os benefícios, articula a oferta de programas complementares e se encarrega da execução das ações de fiscalização e controle, seja diretamente ou em parceria com órgãos públicos 8 e instâncias de controle social 9 .

Os ministérios da Saúde e da Educação, por sua vez, são responsáveis pela coordenação, apoio e fiscalização do acompanhamento das condicionalidades em suas respectivas áreas,

\footnotetext{
7 Conforme regulamentado pelo Art. $4^{\circ}$ do Decreto $n^{0} 5.209$, de 17 de setembro de 2004.

8 Em janeiro de 2005, o MDS firmou convênios com o Tribunal de Contas da União, a Controladoria Geral da União, o Ministério Público Federal e os Ministérios Públicos Estaduais para fortalecer os mecanismos de controle sobre o PBF. Com isso, configurou-se a denominada 'Rede Pública de Fiscalização do Programa Bolsa Família. ${ }^{9} \mathrm{~A}$ formalização de instância de controle social intersetorial e paritária foi uma das condições demandadas aos municípios para efetivarem a adesão ao PBF, a ser discutido mais adiante.
} 
consolidando e repassando as respectivas informações de suas áreas ao MDS, de acordo com os fluxos e prazos definidos.

O Programa prevê o controle social da Bolsa Família em nível municipal. Há uma instrução normativa de 20 de maio de 2005, que estabelece os critérios para composição de um Conselho Municipal, respeitando a intersetorialidade e a paridade entre governo e sociedade, órgão de caráter permanente, com as funções de acompanhar, avaliar e fiscalizar a execução do PBF. Salienta-se que os municípios tiveram de assinar um termo de adesão ao MDS, comprometendo-se com a implantação do controle social.

\subsection{Identificação de Critérios de Seleção e Mecanismos de Seleção}

Uma das mais complexas situações a ser enfrentada por programas focalizados como o PBF é a construção de critérios e mecanismos de seleção dos grupos sociais que serão ou não contemplados, de forma a considerar o conjunto de vulnerabilidades sociais a que esses segmentos estão expostos. Com efeito, os mecanismos capazes de promover a inclusão dos grupos que necessitam de uma dada política serão tão mais efetivos quanto sua capacidade de captar estas distintas vulnerabilidades (MAGALHÃES ET AL., 2004).

Outro importante desafio relacionado aos programas sociais focalizados diz respeito à forma como se processa a seleção dos beneficiários. No caso do PBF, essa seleção é realizada por meio do Cad-Único do governo federal - instituído em 2001, ainda no governo de Fernando Henrique Cardoso - cujo objetivo é uniformizar as informações sobre possíveis beneficiários do PBF e demais programas sociais, propondo-se também a subsidiar o planejamento de políticas públicas dos diferentes níveis de governo (SENNA ET AL., 2007).

Num esforço para compreender as razões pelas quais ocorre a retomada da família como prioridade de intervenção nas duas últimas décadas, Carvalho (1997) argumenta que a abordagem sobre o tema família adquire novas especificidades em razão do reconhecimento de uma inequívoca situação de desemprego estrutural que afeta a já frágil capacidade das famílias enfrentarem os desafios de reprodução social de seus membros. 
De acordo com Draibe (1997), a decisão de se tomar a família como unidade de intervenção está respaldada no argumento de que as políticas de proteção à família teriam maior potencial de impactar as condições de vida da população pobre.

Com base nestas preocupações e considerando as transformações recentes na configuração das famílias brasileiras, O PBF procura incorporar um conceito mais amplo de família, no qual se verifica uma tendência de rompimento com a ideia tradicional de família nuclear. Nessa direção, consta no artigo $2^{\circ}$, parágrafo $1^{\circ}$, da lei de criação do PBF a definição de família como uma "unidade nuclear, eventualmente ampliada por outros indivíduos que com ela possuam laços de parentesco ou afinidade, que forme um grupo doméstico, vivendo sob o mesmo teto e que se mantém pela contribuição de seus membros" (BRASIL, 2012).

Diferentemente dos programas de transferência de renda anteriores, que consideravam inelegíveis as famílias sem filhos, gestantes ou nutrizes, o Bolsa Família amplia, até certo ponto, seu escopo de atendimento ao permitir o acesso desse tipo de família ao Programa. Importante salientar que se trata, ainda, de uma perspectiva restritiva, haja vista que o acesso das famílias sem filhos é somente permitido àquelas que estiverem em situação de pobreza extrema (SENNA ET Al., 2007).

Draibe et al., (1998), ao analisarem os programas de transferência de renda desenvolvidos nos anos 1990, assinalam que o foco na família foi a forma encontrada pelos formuladores de tais políticas para atingir seu principal público-alvo - crianças e adolescentes - e incluí-los em outras políticas, sobretudo a de educação, tornando pais e responsáveis meros intermediários nesse processo. Se, de algum modo, tal análise pode ser transposta para o PBF, é necessário pensar em que medida a família é (ou não), na realidade, a unidade privilegiada de intervenção do Programa.

\subsection{Critérios de seleção}

A situação socioeconômica das famílias é determinada, para efeito da gestão do Programa, a partir do critério de renda, com limites 
definidos com base em estudos desenvolvidos pelo MDS com o apoio do Instituto de Pesquisa Econômica Aplicada-Ipea e do IBGE.

\section{Valores e tipos de benefícios}

Os valores dos benefícios pagos pelo PBF no país variam de $R \$$ 32,00 a $R \$ 306,00$ de acordo com a renda mensal da família por pessoa, com o número de crianças e adolescentes de até 17 anos e número de gestante e nutrizes componentes da família. O Programa tem quatro tipos de benefícios: a) básico; b) variável; c) variável vinculada ao adolescente e, d) variável de caráter extraordinário.

O Benefício Básico, de $\mathrm{R} \$ 70,00$ é pago às famílias consideradas extremamente pobres, com renda mensal de até $R \$ 70,00$ por pessoa, mesmo que elas não tenham crianças, adolescentes ou jovens.

O Benefício Variável, de $\mathrm{R} \$ 32,00$ é pago às famílias pobres, com renda mensal de até $R \$ 140,00$ por pessoa, desde que tenham crianças e adolescentes de até 15 anos, gestantes e/ou nutrizes. Cada família pode receber até cinco benefícios variáveis, ou seja, até $R \$ 160,00$.

O Benefício Variável Vinculado ao Adolescente-BVJ, de R\$38,00 é pago a todas as famílias do Programa que tenham adolescentes de 16 e 17 anos frequentando a escola. Cada família pode receber até dois benefícios variáveis vinculados ao adolescente, ou seja, até $R \$ 76,00$. 
O Benefício Variável de Caráter Extraordinário-BVCE é pago às famílias nos casos em que a migração dos Programas Auxílio-Gás, Bolsa Escola, Bolsa Alimentação e Cartão Alimentação para o PBF cause perdas financeiras. O valor do benefício varia de caso a caso.

\section{Condicionalidades}

As condicionalidades são os compromissos assumidos tanto pelas famílias beneficiárias do PBF quanto pelo poder público para ampliar o acesso e seus direitos básicos. Por um lado, as famílias devem assumir e cumprir esses compromissos para continuar recebendo o benefício. Por outro, as condicionalidades responsabilizam o poder público pela oferta dos serviços públicos de saúde, educação e assistência social.

Em relação aos serviços de saúde, o PBF determina que as famílias beneficiárias assumam o compromisso de acompanhar o cartão de vacinação e o crescimento e desenvolvimento das crianças menores de sete anos. As mulheres na faixa de 14 a 44 anos também devem fazer 0 acompanhamento e, se gestantes ou nutrizes (lactantes), devem realizar o pré-natal e o acompanhamento da sua saúde e do bebê.

$\mathrm{Na}$ educação, todas as crianças e adolescentes entre seis e cinco anos devem estar devidamente matriculados e com frequência escolar mensal mínima de $85 \%$ da carga horária. Já os estudantes entre 16 e 17 anos devem ter frequência de, no mínimo, 75\%.

$\mathrm{Na}$ área de assistência social, crianças e adolescentes com até 15 anos em risco ou retiradas do trabalho infantil pelo Peti, devem participar dos Serviços de Convivência e Fortalecimento de VínculosSCFV do Peti e obter frequência mínima de $85 \%$ da carga horária mensal.

As famílias que estiverem inadimplentes com relação ao cumprimento das condicionalidades estão sujeitas a uma série de sanções, que vão desde o bloqueio do benefício por 30 dias até o seu cancelamento. Tais regras podem criar, em verdade, um processo de exclusão que alarga ainda mais a distância entre o PBF e a lei de autoria do senador Eduardo Suplicy, que institui uma renda básica de cidadania universal e incondicional.

Além disso, a ausência de registro do resultado do acompanhamento das condicionalidades nos sistemas de informação, definidos pelos ministérios da educação e saúde, poderá, também, acarretar em bloqueio e perda do benefício, a critério do MDS. A 
legislação preserva as famílias de qualquer sanção somente quando ficar comprovado que o cumprimento das condicionalidades foi prejudicado em razão de problemas relativos à oferta de serviços por parte dos municípios (SENNA ET Al., 2007).

\section{IMPACTOS DO PROGRAMA BOLSA FAMÍLIA NA ALFABETIZAÇÃO DOS BENEFICIÁRIOS DO PROGRAMA NO MUNICÍPIO DE SANTA MARIA - RS}

Nesta seção, primeiro é efetuada a caracterização do Município de Santa Maria e da SMAC. Num segundo momento são abordadas as particularidades dos procedimentos metodológicos do estudo de caso realizado e, na parte final, segue a análise econométrica realizada a partir dos dados dos Censos 2000 e 2010, específicos das variáveis populacionais e de alfabetização e das informações da SMAC.

\subsection{Caracterização do Município de Santa Maria - RS}

Segundo o Censo Demográfico do ano de 2010, a população do Município de Santa Maria é de 261.031 habitantes. Sua posição geográfica situa-se no centro do estado, constituindo-se na $5^{\text {a }}$ cidade mais populosa do Rio Grande do Sul e, isoladamente, a maior de sua região que possui quase 1 milhão de habitantes. Com relação aos aspectos geográficos, possui área de $1788,129 \mathrm{~km}^{2}$ e densidade de $145,98 \mathrm{hab} / \mathrm{km}^{2}$.

Os limites geográficos de Santa Maria - RS são distribuídos da seguinte maneira: (ao Norte Itaara, Julio de Castilhos e São Martinho da Serra); ao Sul, (São Gabriel e São Sepé); a Leste (Silveira Martins, Restinga Seca e Formigueiro); e a Oeste (São Pedro do Sul e Dilermando de Aguiar).

O Município de Santa Maria é constituído de uma população predominantemente urbana (95\%), segundo o Censo Demográfico de 2010, portanto, um município nitidamente urbano. Este município é enquadrado de acordo com os critérios do MDS, como município de grande porte, devido a população de mais de duzentos mil habitantes. A implementação do Centro de Referência Especializado de Assistência Social-CREAS é de 01 a cada 200.000 habitantes. 


\subsection{O desenvolvimento Recente do Programa Bolsa Família em Santa}

\section{Maria}

Em 2010, o Município Santa Maria contou com 18.379 famílias cadastradas no Cadúnico. Destas, 10.892 conseguiram o benefício do PBF. É importante ressaltar que, nesse município, 26\% recebem o benefício básico e $20 \%$ pertencem ao grupo receptor do benefício variável.

No que diz respeito às características gerais dos beneficiários do PBF no município estudado, as mulheres são a maioria, com $57 \%$ dos benefícios, enquanto que os homens perfazem $43 \%$ do total.

A Figura 1 apresenta o número de beneficiários do PBF no município, considerando os 12 bairros com maior número de beneficiários. Cabe ressaltar que esses 12 bairros percebem $62 \%$ do total de benefícios destinados ao PBF no Município de Santa Maria, e somente o bairro Santa Marta possui 1.443 famílias beneficiarias, seguido pelo Bairro Salgado Filho, com 696 famílias beneficiárias. 


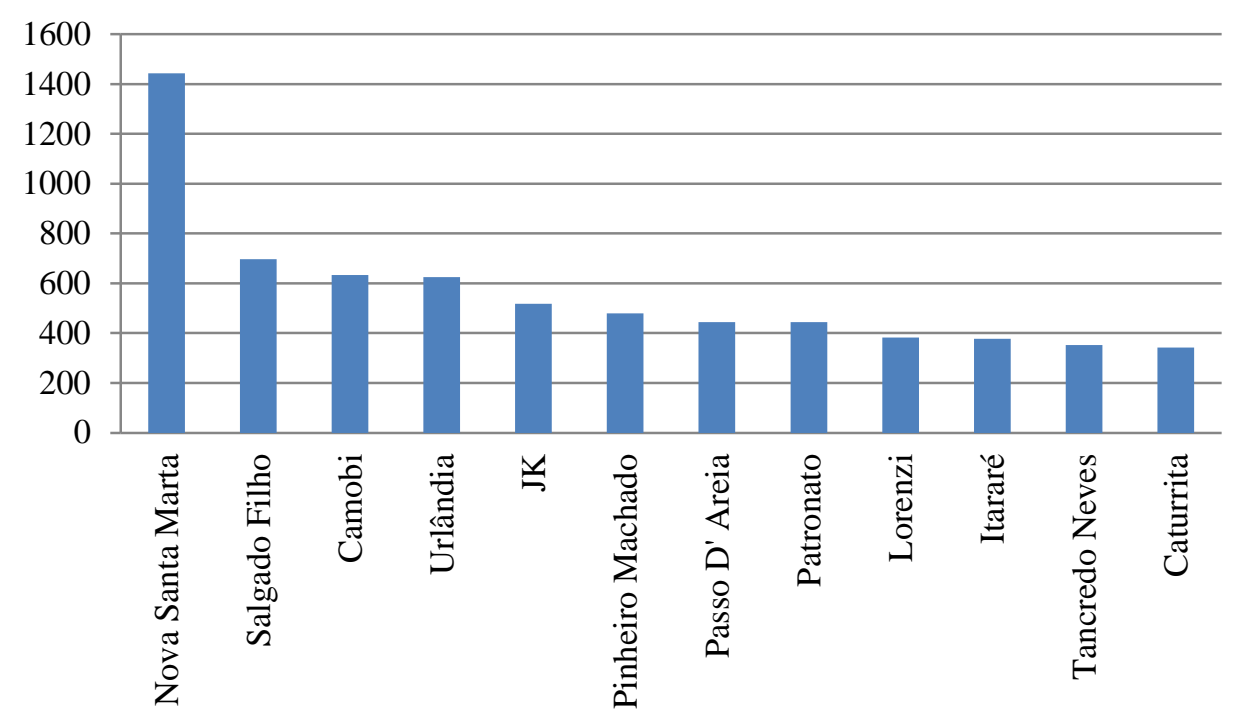

Figura 1. Bairros com mais Famílias Beneficiárias.

Fonte: Dados IBGE.

\subsection{Atores Sociais Municipais de Gestão do Programa Bolsa Família}

A entidade municipal que abriga o desenvolvimento do PBF no município é a SMAC. Essa Secretaria Municipal é a Gestora do PBF, possui um Departamento chamado de Cadastro Único, responsável pelo cadastramento das famílias com perfil de até meio salário mínimo per capita, realiza o preenchimento dos formulários físicos e após digita os dados de todas as famílias no aplicativo on-line da CEF. O Departamento de Cadastro Único desenvolve articulações internas com - Programa de Atenção Integral às Famílias através dos Centros de Referência de Assistência Social, que atendem os beneficiários do PBF e, também impulsiona ações intersetoriais com as Secretarias Municipais de Educação, Habitação e Saúde.

\subsection{Procedimentos Metodológicos}

Para uma melhor análise da problemática que objetiva o estudo, optou-se por buscar informações de dados secundários do IBGE e uma pesquisa de campo. Dessa forma, as informações se complementam de modo a constituir a obtenção das informações necessárias ao desenvolvimento do modelo econométrico, cujos resultados, à luz das 
contribuições da literatura especializadas, permitem elucidar a proposição do estudo de caso. 


\subsubsection{Base de dados secundários e alterações metodológicas}

As informações disponíveis no IBGE e pertinentes ao estudo proposto são: população municipal, alfabetização por bairros, saneamento e renda. Considerando as mudanças metodológicas de apresentação dos dados no Censo, nos anos de 2000 e 2010 , optou-se por uma análise que se circunscreve as variáveis populacionais e de alfabetização, pois apenas essas permitem uma comparabilidade, sem a necessidade de ajustes de informações.

Assim, procedeu-se um ajustamento matemático capaz de permitir a estimação de uma análise de regressão múltipla, utilizando os dados de 2000 e 2010 , para todos os bairros que receberam recursos do PBF em 2010 e que possuíam correspondência com os existentes no ano 200010. A escolha desses dois anos decorre da necessidade de comparação de dois momentos históricos distintos, respectivamente anterior e posterior à implantação do PBF no município. A análise da escolaridade em função dos investimentos no PBF poderia ser estendida para as outras variáveis se fosse possível o acesso aos valores antes e depois da implantação do referido Programa. A dificuldade consistiu na mudança de metodologia adotada pelo IBGE na obtenção dos dados.

Para a estimação da regressão, foram utilizados os dados dos Censos de 2000 e 2010 , referentes às seguintes variáveis: alfabetização e população de todos os bairros que receberem recursos do PBF em 2010 e que tinham correspondência nas informações por bairro em $2000^{11}$.

O modelo de regressão simples adotado foi $Y=f(x)$, sendo que " $Y$ " (variável dependente ou explicada) é acréscimo na porcentagem de alfabetizados e "X" (variável independente ou explicativa) é a proporção de investimentos no PBF.

Y= alfabetizados / população de 2010 - alfabetizados / população de 2000

\footnotetext{
10 Portanto, trata-se da análise de 22 bairros do Município de Santa Maria - RS.

11 É preciso esclarecer que houve uma mudança através do Plano Diretor de 2005 na divisão dos bairros, eram 22 bairros e após a alteração passou para 42 bairros. Considerando que muitos foram desmembrados, optou-se por analisar apenas aqueles que não sofreram mudança. $O$ bairro Centro também foi excluído da amostra por não disponibilizar a informação acerca do número de beneficiários.
} 
$X=$ Número de pessoas que recebiam o benefício 2010 / população

A regressão simples estimada resultou na seguinte equação:

$\mathrm{Y}=7,375+0,54 \mathrm{X}$, o que equivale afirmar que quanto maior a proporção de pessoas que recebem os benefícios do PBF, maior o acréscimo na proporção de alfabetizados.

\begin{tabular}{|l|c|c|}
\hline \multicolumn{1}{|c|}{ Censo Demográfico } & $\mathbf{2 0 1 0}$ & $\mathbf{2 0 0 0}$ \\
\hline Média & 154,30 & 148,53 \\
\hline Variância & 264919,11 & 283985,54 \\
\hline Desvio Padrão & 514,7 & 532,9 \\
\hline Coef. De Variação & 3,34 & 3,59 \\
\hline
\end{tabular}

Quadro 1. Média por Bairro da Proporção de Alfabetizados.

Fonte: Dados IBGE.

Considerando a margem de erro calculada $(0,079$, ou então com uma margem de confiança de 0,921), o Quadro 1 mostra que a variância em 2010 é significativamente inferior à variância em 2000, lembrando que este último ainda não contava com a existência do PBF. Dessa forma, pode-se afirmar que a implementação do PBF contribuiu para a maior homogeneização dos bairros, no que diz respeito aos níveis de alfabetização.

\subsubsection{A determinação da amostra}

O estudo de caso parte da utilização de dados fornecidos pela Secretaria de Assistência Social do Município de Santa Maria que, além do fornecimento das estatísticas mais gerais, possibilitou o acesso às informações, mormente às quantitativas descritas no item 4.1. Dessa forma, tem-se uma população de 10.892 famílias distribuídas nos diferentes bairros do município.

Pode-se, a partir do recadastramento das famílias, aplicar o questionário, o que facilitou o acesso aos beneficiários e reduziu os custos e o tempo na busca dessas informações que, de outro modo, teriam que ser buscadas nos domicílios, o que certamente inviabilizaria esta pesquisa. $O$ intuito da pesquisa de campo está vinculado com um dos objetivos do artigo que consistiu em conhecer e descrever as 
particularidades de educação, saúde, renda e condições infraestruturais dos domicílios.

Os questionários foram aplicados a 75 pessoas no mês de maio/2012, aproveitando o período de recadastramento na Secretaria de Assistência Social do município. Tal amostra se justifica considerando a baixa variabilidade na maioria das questões relevantes na análise. A gestora do Programa contribuiu para o êxito desta pesquisa, uma vez que, além das informações prestadas, proporcionou a logística adequada, e a intervenção que permitiu a tranquilidade dos entrevistados. Após a aplicação dos instrumentos, realizou-se a análise de conteúdo e a interpretação dos dados.

\section{RESULTADOS DA PESQUISA DE CAMPO: DESCRIÇÃO DO DESENVOLVIMENTO RECENTE DO PROGRAMA DE TRANSFERÊNCIA DE RENDA- BOLSA FAMÍLIA NO MUNICÍPIO DE SANTA MARIA - RS}

Esta parte mostra os resultados obtidos na pesquisa de campo realizada na sede da Secretaria de Assistência Social de Santa Maria, a partir de questionário semiestruturado para 75 beneficiários do Programa, com ênfase nos seguintes aspectos: Grau de Escolaridade das Beneficiárias do PBF; Relação de Trabalho; Tipos de Desempregos; Renda Familiar; Estado Civil; Número de Filhos por Famílias; Acesso à Saúde; Acesso à Educação e Conhecimento das Condicionalidades do PBF.

\subsection{Características dos Entrevistados}

Considerando-se os dados do Quadro 2, é possível notar que a escolaridade da maioria dos beneficiárias do PBF, ou seja, 57,33\% são pessoas que possuem ensino fundamental incompleto, já que acessaram a escola, embora sem conseguir concluir os estudos. O percentual de analfabetismo das entrevistadas é considerado baixo, ou seja, apenas 1,33\%. Essas informações denotam a importância de inclusão de um número cada vez maior de pessoas no PBF.

\begin{tabular}{|l|c|c|}
\hline \multicolumn{1}{|c|}{ Escolaridade } & Número & Percentual(\%) \\
\hline $\begin{array}{l}\text { Ensino Fundamental } \\
\text { Incompleto }\end{array}$ & 43 & 57,33 \\
\hline
\end{tabular}




\begin{tabular}{|l|c|c|}
\hline Ensino Fundamental Completo & 16 & 21,33 \\
\hline Ensino Médio Incompleto & 2 & 2,67 \\
\hline Ensino Médio Completo & 13 & 17,33 \\
\hline Analfabeto & 1 & 1,33 \\
\hline Não Respondeu & - & - \\
\hline Total & 75 & 100 \\
\hline
\end{tabular}

Quadro 2. Grau de Escolaridade das Beneficiárias do Programa Bolsa Família ${ }^{12 .}$

Fonte: Pesquisa de campo, maio de 2012.

A pesquisa mostrou que $60 \%$ das entrevistadas encontram-se desempregadas, índice bastante significativo, o que demonstra a dependência financeira das famílias em relação ao PBF.

\begin{tabular}{|l|c|c|}
\hline \multicolumn{1}{|c|}{ Situação } & Número & Percentual (\%) \\
\hline Trabalho & 30 & 40 \\
\hline Desempregados & 45 & 60 \\
\hline Não respondeu & - & - \\
\hline Total & 75 & 100 \\
\hline
\end{tabular}

Quadro 3. Relações de Trabalho das Entrevistadas.

Fonte: Pesquisa de campo, maio de 2012.

Das 45 beneficiárias desempregadas encontradas, verificou-se que a maioria encontra-se em desemprego aberto; estão fora do mercado de trabalho e não estão nem realizando trabalho informal, 0 que ocorre com 24 entrevistadas $44 \%$.

\begin{tabular}{|l|c|c|}
\hline \multicolumn{1}{|c|}{ Tipos } & Número & Percentual (\%) \\
\hline Aberto & 15 & 33,33 \\
\hline Trabalho Precário & 11 & 24,44 \\
\hline Desalento & 9 & 20 \\
\hline Nunca Trabalhou & 10 & 22,22 \\
\hline Total & 45 & 100 \\
\hline
\end{tabular}

Quadro 4. Tipos de Desempregos das Entrevistadas

Fonte: Pesquisa de campo, maio de 2012.

12 Há que se informar que todos os entrevistados foram do sexo feminino. Tal resultado não se constituiu a partir de uma ação intencional, porém decorre do fato de que nos dias em que foram aplicados os formulários, aleatoriamente, na Secretaria, coincidentemente, havia apenas pessoas do sexo feminino. 
Utilizou-se, como referência, o critério de classificação do Departamento Intersindical de Estatística e Estudos SocioeconômicosDIEESE para a construção desses indicadores, de acordo com o Glossário de termos técnicos de 2001 :

a) desemprego aberto: pessoas que procuraram trabalho de maneira efetiva nos 30 dias anteriores ao da entrevista e não exerceram nenhum trabalho nos sete últimos dias;

b) desemprego oculto pelo trabalho precário: pessoas que realizam trabalhos precários - algum trabalho remunerado ocasional de autoocupação - ou pessoas que realizam trabalho não remunerado em ajuda a negócios de parentes e que procuraram mudar de trabalho nos 30 dias anteriores ao da entrevista ou que, não tendo procurado nesse período, o fizeram sem êxito até 12 meses atrás;

c) desemprego oculto pelo desalento: pessoas que não possuem trabalho, nem procuraram nos últimos 30 dias anteriores ao da entrevista, por desestímulos do mercado de trabalho ou por circunstâncias fortuitas, mas apresentaram procura efetiva de trabalho nos últimos 12 meses.

\begin{tabular}{|l|c|c|}
\hline \multicolumn{1}{|c|}{ Tempo } & Número & Percentual (\%) \\
\hline Menos de 3 meses & 4 & 8,89 \\
\hline Ate 6 meses & 4 & 8,89 \\
\hline 6 meses a 12 meses & 9 & 20 \\
\hline 1 ano a 3 anos & 7 & 15,56 \\
\hline 4 a 6 anos & 2 & 4,44 \\
\hline 7 a 10 anos & 3 & 6,67 \\
\hline Mais de 10 anos & - & - \\
\hline Nunca Trabalhou & 10 & 22,22 \\
\hline Nunca assinou carteira & 2 & 4,44 \\
\hline Não respondeu & 4 & 8,89 \\
\hline Total & 45 & 100 \\
\hline
\end{tabular}

Quadro 5. Tempo de Desemprego das Entrevistadas.

Fonte: Pesquisa de campo, maio de 2012.

Constatou-se que a maior parte dos entrevistados $(22,22 \%)$ nunca trabalhou, alegando serem donas de casa e 15,56\% uma média de 1 a 3 anos que estão sem trabalho, ficando evidente a dependência do PBF em 
relação aos recursos financeiros, visto que é a única renda fixa de considerável parcela dessas famílias.

Observou-se que $40 \%$ das entrevistadas são solteiras, sendo que as famílias são consideradas monoparentais, ou seja, as mulheres são chefes das famílias e cuidam seus filhos sozinhas, sem presença masculina. Com relação ao pré-natal, verificou-se que $100 \%$ das beneficiárias informaram ter realizado o pré-natal. Outra informação que merece destaque diz respeito ao acesso às unidades básicas de saúde. Nesse quesito, todas as entrevistadas possuem acesso às referidas unidades e conhecem as exigências dos programas em relação às condicionalidades da saúde. 


\subsection{Características das Famílias}

Tendo em vista que a categoria de análise não se circunscreve às pessoas, porém, famílias, a pesquisa de campo caracterizou a variável renda familiar (utilizou-se, como base, o salário mínimo nacional de R\$ 622,00 reais), número de filhos, utilização de serviços básicos, aspectos referentes à saúde e educação.

\begin{tabular}{|l|c|c|}
\hline \multicolumn{1}{|c|}{ Renda } & Número & Percentual (\%) \\
\hline Menos 1 SM & 54 & 72 \\
\hline 1 SM & 18 & 24 \\
\hline Mais 1 SM & 3 & 4 \\
\hline Total & 75 & 100 \\
\hline
\end{tabular}

Quadro 6. Renda Familiar.

Fonte: Pesquisa de campo, maio de 2012.

Quanto à renda total familiar, constatou-se que $72 \%$ das famílias informaram receber menos de um salário mínimo por mês, o que demonstra a fragilidade econômica e social dessas famílias. Assim, 2/3 das famílias possuem até dois filhos. Ao se considerar - conforme visto na seção 5.3.1 - que $40 \%$ das entrevistadas serem solteiras, isso permite afirmar que a maior parte das famílias pertencentes ao universo desta pesquisa possuem, apenas três membros. Isso mostra que a renda familiar per capita na maior parte dos casos é inferior a 200, 00 por mês.

\begin{tabular}{|l|c|c|}
\hline \multicolumn{1}{|c|}{ N $^{\mathbf{2}}$ de Filhos } & Número & Percentual (\%) \\
\hline 1 Filho & 25 & 33,33 \\
\hline 2 Filhos & 25 & 33,33 \\
\hline 3 Filhos & 11 & 14,67 \\
\hline 4 Filhos & 6 & 8 \\
\hline Mais de 5 Filhos & 8 & 10,67 \\
\hline Total & 75 & 100 \\
\hline
\end{tabular}

Quadro 7. Número de Filhos por Famílias. Fonte: Pesquisa de campo, maio de 2012. 
Constatou-se, também, que 98 (67\%) das beneficiárias realizam acompanhamento nutricional dos seus filhos e apenas 1,33\% não realiza. Além disso, observou-se que $100 \%$ das beneficiárias levam seus filhos para serem vacinados.

No quesito educação, há que se salientar que todos os integrantes das famílias possuem acesso à educação. Apenas cinco do total de entrevistados não possuem filhos em idade escolar. Do ponto de vista do conhecimento das condicionalidades, todos os entrevistados afirmaram conhecer as exigências do PBF. 


\begin{tabular}{|l|c|c|}
\hline \multicolumn{1}{|c|}{ Repetência Escolar } & N $^{\circ}$ & $\%$ \\
\hline Sim & 33 & 44 \\
\hline Não & 42 & 56 \\
\hline Total & 75 & 100 \\
\hline
\end{tabular}

Quadro 8. Repetência Escolar.

Fonte: Pesquisa de campo, maio de 2012.

Pode-se observar que $44 \%$ das famílias pesquisadas tiveram filhos com repetência na escola, e $56 \%$ das famílias não tiveram. Esses resultados podem indicar que apenas os beneficiários indiretos (filhos) permanecem na escola devido à exigência do PBF de atingirem $85 \%$ de frequência escolar. Uma das entrevistadas relatou que há um cuidado em relação à frequência escolar, considerando ser uma exigência para o recebimento continuado do benefício.

\begin{tabular}{|l|c|c|}
\hline \multicolumn{1}{|c|}{ Quantas Vezes } & Número & Percentual (\%) \\
\hline Sem reprovação & 42 & 56 \\
\hline 1 Vez & 17 & 22,67 \\
\hline 2 Vezes & 10 & 13,33 \\
\hline 3 Vezes & 5 & 6,67 \\
\hline Mais de 3 Vezes & 1 & 1,33 \\
\hline Total & 75 & 100 \\
\hline
\end{tabular}

Quadro 9. Número de Vezes que Houve Reprovação Escolar por Família.

Fonte: Pesquisa de campo, maio de 2012.

Para conhecer de forma específica a situação dos membros familiares em relação à repetência escolar, perguntou-se quantas vezes os filhos tinham repetido o ano e identificou-se que apenas $56 \%$ das famílias entrevistadas não tiveram reprovação escolar de seus filhos.

\begin{tabular}{|l|c|c|l|c|c|}
\hline \multicolumn{1}{|c|}{ Idade } & $\mathbf{N}^{\mathbf{2}}$ & $\%$ & \multicolumn{1}{|c|}{ Série } & $\mathbf{N}^{\circ}$ & $\%$ \\
\hline 0 a 5 anos & 19 & 14,84 & Educação Infantil & 10 & 7,81 \\
\hline 6 a 10 anos & 50 & 39,06 & $1^{\text {a }}$ a $4^{\text {a }}$ série & 52 & 40,63 \\
\hline $\begin{array}{l}11 \text { a } 14 \\
\text { anos }\end{array}$ & 33 & 25,78 & $5^{\text {a }}$ a $8^{\text {a }}$ série & 41 & 32,03 \\
\hline 15 a 18 & 23 & 17,97 & Ensino Médio & 10 & 7,81 \\
\hline
\end{tabular}




\begin{tabular}{|l|c|c|l|c|c|}
\hline anos & & & Incompleto & & - \\
\hline $\begin{array}{l}19 \text { a } 21 \\
\text { anos }\end{array}$ & 3 & 2,34 & $\begin{array}{l}\text { Ensino Médio } \\
\text { Completo }\end{array}$ & - & - \\
\hline $\begin{array}{l}22 \text { a } 30 \\
\text { anos }\end{array}$ & - & - & EJA & 3 & 2,34 \\
\hline Mais de 30 & - & - & Universidade & - & - \\
\hline Total & 128 & 100 & Não Estudando & 12 & 9,38 \\
\hline & & & Total & 128 & 100 \\
\hline
\end{tabular}

Quadro 10. Idade dos filhos X Série escolar.

Fonte: Pesquisa de campo, maio de 2012.

Constatou-se que existem $14,84 \%$ de crianças de 0 a 6 anos e apenas $7,81 \%$ em escolas de educação infantil; $17,97 \%$ de adolescentes e apenas $7,81 \%$ no ensino médio, e $9,38 \%$ não estudam. Nenhum dos filhos beneficiários possui ensino completo, apesar de muitos terem idade suficiente para tal.

Percebe-se, portanto, que se verifica uma baixa escolaridade das famílias beneficiárias do PBF, o que, futuramente, pode ser revertido se os que estão frequentando o ensino fundamental continuarem os estudos.

\section{CONSIDERAÇÕES FINAIS}

O presente artigo teve por objetivo analisar as implicações do PBF na alfabetização dos beneficiários e caracterizar de forma mais abrangente a situação de variáveis como renda per capita das famílias, e na frequência escolar dos estudantes vinculados ao PBF no Município de Santa Maria - RS.

Foram utilizadas informações primárias e secundárias como base de dados na consecução de uma análise econométrica de regressão simples, para concluir que quanto maior a proporção de pessoas que recebem os benefícios do PBF no município, maior o acréscimo na proporção de alfabetizados. Esse resultado constata a importância que o PBF representa nos melhores níveis educacionais no tipo básico. Adicionalmente a essa constatação e não menos importantes sãos resultados acerca do impacto do PBF no concernente a uma maior homogeneização dos diferentes bairros analisados. 
Os dados mais gerais acerca do estudo de campo permitem arrolar uma série de particularidades. Merece destaque o elevado grau de repetência escolar-44\% das famílias teve reprovação dos seus filhos. Considerando a exigência para a continuidade do recebimento do benefício do PBF, que exige $85 \%$ de frequência escolar desses filhos, isso demonstra que o Programa, apesar de importante, é insuficiente para minimizar o problema de repetência escolar.

Tal resultado indica a necessidade premente de coadunar essa política pública a outras iniciativas capazes de minimizar os problemas que impedem muitos filhos em idade escolar deixarem de ir à escola. Certamente, nenhuma política pública é capaz de diminuir todas as adversidades, sendo, sim, necessárias políticas macroeconômicas mais amplas de crescimento econômico que, por sua vez, devem repercutir no aumento da renda per capita combinada com distribuição de renda.

A principal polêmica em torno das condicionalidades do PBF aparece, por um lado, no reconhecimento de que as mesmas têm potencial de pressionar a demanda sobre os serviços de educação e saúde, o que, de certa forma, pode representar uma oportunidade ímpar para ampliar o acesso de um contingente importante da população aos circuitos de oferta de serviços sociais. Todavia, são muitos os desafios, tendo em vista a magnitude e complexidade da questão social e a histórica fragilidade do Estado brasileiro em dar respostas eficazes.

Conclui-se, portanto, que os dados apresentados serão de grande relevância para o Município de Santa Maria, visto a complexidade do PBF e o número expressivo de beneficiários, servindo de importante instrumento de reflexão sobre a implementação deste Programa.

\section{REFERÊNCIAS}

BALDISSERA, A. A Política Social da criança e do adolescente em Pelotas e o Mercado de trabalho. In: Sociedade em Debate, Pelotas: EDUCAT, v. 3, n.1, 1997.

BOSCHETI, I. F. O sistema de proteção social no Brasil e a Política de Assistência Social. Palestra proferida na PUC, PR - Semana do Serviço Social, 2005. 
BRASIL. Ministério do Desenvolvimento Social e Combate à Fome. Programa Bolsa Família. Disponível em:

$<$ http://www.mds.gov.br/bolsafamilia/gestaodescentralizada/legislacao $>$. Acesso em abr. 2012.

CAMPOS F., Antonio Claret Transferência de renda com condicionalidades e desenvolvimento de capacidades: uma análise a partir da integração dos programas Bolsa Família e Vida Nova no Município de Nova Lima. / Antonio Claret Campos Filho:Rio de Janeiro: s.n., 2007.

CARVALHO, M. C. B. A priorização da família na agenda da política social. In:-__-_. (Org.) A família contemporânea em debate. São Paulo: Cortez/ EDUC, p. 11-21. 1997.

COLARES, M. S. P. Programa de transferência de renda no Brasil e seus desafios futuros. Disponível em:

$<$ http://www.sinteseeventos.com.br/bien/pt/papers/monicacolaresPRO GRAMTRANSFEOFINCOMEINBRAZILANDITSFUTURECHALLENGES.pdf $>$. Acesso em 08 maio 2012.

COUTO, B. R.. O direito social e a assistência social na sociedade brasileira: uma equação possível? São Paulo: Cortez, 2004.

DRAIBE, S. A construção institucional da política brasileira de combate à pobreza: perfis, processos e agenda. Caderno de Pesquisa n.34. Campinas: NEPP/ UNICAMP, 1997.

FALCÃO, M. C. A seguridade na travessia do Estado Assistencial brasileiro. Os direitos (dos desassistidos sociais). São Paulo: Cortez, 1995.

FONSECA, A. M. M.; VIANA, A. L. A. Direito à saúde, atenção básica e transferências condicionadas de renda na América Latina. Ciência \& Saúde Coletiva, Rio de Janeiro, v.12, n.6, p.1505-1512, 2007. 
MAGALHÃES, R. et al. Estudo da implementação do Programa Bolsa Família no estado do Rio de Janeiro. Relatório de Pesquisa CNPq. Rio de Janeiro: Fundação Osvaldo Cruz, 2005.

MOURA, Alessandra Ballinhas de. Avaliação da Eficácia do Programa Bolsa Família na cidade de Pelotas - RS. 2009. 126f. Dissertação (Mestrado em Política Social) -Universidade Católica de Pelotas, Pelotas, 2009.

PISÓN, J. M. Políticas de bien estar: un estudio sobre los derechos sociales. Madrid: Tecnos, 1998.

POCHMANN, M. (org.). Reestruturação produtiva: perspectivas de desenvolvimento local com inclusão social. Petrópolis: Vozes, 2004.

ROCHA. S. Pobreza no Brasil: afinal de que se trata? $1^{\text {a }}$ ed. Rio de Janeiro: FGV, 2003.

SECRETARIA DE MUNICÍPIO DE ASSISTÊNCIA SOCIAL, CIDADANIA E DIREITOS HUMANOS. Programa Bolsa Família. Disponível em:

< http://www.santamaria.rs.gov.br/smasc/>. Acesso em maio 2012.

SENNA, M. C. M.; MONNERAT, B. G.; SCHOTTZ, V.; MAGALHÃES, R. Programa Bolsa Família: nova institucionalidade no campo da política social brasileira? Revista Katályses, Florianópolis, v. 10, n. 1, p. 86-94 jan./jun. 2007.

SIMIONATO, I. Reforma do estado e políticas públicas: implicações para a sociedade civil e para a profissão. Disponível em:

$<$ http://www.portalsocial.ufsc.br/crise_estado.pdf $>$. Acesso em 28 nov. 2011.

SILVA, M. O.; GIOVANNI, G. A Política Social brasileira no século XXI: A prevalência dos Programas de transferência de Renda. São Paulo: Cortez, 2004. 
SILVA E SILVA, M. O. Especificidades do sistema de proteção social no Brasil. São Luis: (mimeo), UFMA, 1997.

SISTEMA IBGE DE RECUPERAÇÃO AUTOMÁTICA - SIDRA. Banco de Dados Agregados. Disponível em:

$<$ http://www.sidra.ibge.gov.br/cd/cd2010universo.asp >. Acesso em mar. 2012.

SUPLICY, E.M. Renda de Cidadania: a saída é pela porta. São Paulo: Cortez, 2002.

Submetido em 23/07/2013.

Aprovado em 06/10/2015. 
Sobre as autoras

Rita Inês Paetzhold Pauli

Professora Associada e pesquisadora do Curso de Ciências Econômicas da Universidade Federal de Santa Maria - RS.

Endereço: Rua Adão Schneider, 202, ap 101, Bairro Presidente João Goulart. 97090010 - Santa Maria, RS, Brasil

E-mail rita.pauli@gmail.com

\section{Laura Haesbaert}

Economista e Pesquisadora pela Universidade Federal de Santa Maria - RS.

E-mail: laurahaesbaert@gmail.com 